\title{
DANIEL 7: OS CINCO SERES PERANTE O TRIBUNAL DIVINO - COMPREENSÃO DE REVOLTA NO TEXTO E PRINCIPAIS FATORES QUE MOTIVARAM A REVOLUÇÃO ARMADA
}

\author{
Gabriel Santana Silva'; ${ }^{1}$ Ágabo Borges de Souza ${ }^{2}$; Diego Lino Silva e Andrey Sá \\ Barreto Souza ${ }^{4}$ \\ 1. Bolsista PIBIC/CNPq, Graduando em Licenciatura em História, Universidade Estadual de Feira de Santana, e- \\ mail: mssgabrielsantana@gmail.com \\ 2. Orientador, Departamento de Ciências Humanas e Filosofia, Universidade Estadual de Feira de Santana, e-mail: \\ dragabo@hotmail.com \\ 3. Participante do projeto As Escolas Filosóficas do II sec. a.C. e o Movimento Apocalíptico de Daniel, \\ Departamento de Ciências Humanas e Filosofia, Universidade Estadual de Feira de Santana, e-mail: \\ historia.lino@gmail.com \\ 4. Participante do projeto As Escolas Filosóficas do II sec. a.C. e o Movimento Apocalíptico de Daniel, \\ Departamento de Ciências Humanas e Filosofia, Universidade Estadual de Feira de Santana, e-mail: \\ andrey sa@hotmail.com
}

PALAVRAS-CHAVE: Apocalíptica; Revolta; Daniel.

\section{INTRODUÇÃO}

O encontro entre as culturas, Helênica e Judaica, foi marcado por conflitos entre os modos de viver. Nesse período surge a literatura apocalíptica que tinha por objetivo falar ao seu tempo, usando de alegorias para denunciar e resistir ao império opressor. $\mathrm{O}$ texto de Daniel 7, que narra uma espécie de tribunal onde quatro seres de aparência monstruosa serão julgados, e depois a introdução de "um como um filho de homem" que contrapõe os animais citados, pode ser interpretado por meio da história-cultural, e é o objetivo desse trabalho, compreendendo assim o contexto social e como se deu a resistência judaica.

\section{MATERIAL E MÉTODOS OU METODOLOGIA}

A Bíblia, além de importante livro canônico para a cultura e religião ocidental, é uma literatura, e sendo assim, é uma fonte histórica, mesmo que sujeita às mais diversas interpretações, além de ser uma construção humana dentro do tempo. Bloch disse que tudo que o homem escreve, fabrica e toca, pode e deve informar sobre ele ${ }^{1}$, ainda, que o historiador deve ser como um ogro cujo faro está sempre sendo atraído para as construções humanas dentro da história ${ }^{2}$. A forma que se falava de história na antiguidade tem características especificas, como o uso de uma linguagem mítica, que não tinham como objetivo explicar como as coisas aconteceram, mas explicar porque elas são como são ${ }^{3}$. Assim, é importante olhar para o texto de Daniel, capitulo 7, como uma alegoria, não como narrativa histórica. A história-cultural de Chartier que possibilita uma leitura histórica pelo reflexo da literatura, por esse motivo, e com essa

\footnotetext{
${ }^{1}$ BLOCH, Marc. Apologia da História. Jorge Zahar: Rio de Janeiro, 2001, pp. 79.

${ }^{2}$ Ibid., pp. 54.

3 SOUSA, Ágabo Borges Livros dos Inícios e Princípios: O Livro de Gênesis como Base Teológica para a Bíblia Hebraica. Epistêmê VI.11, Feira de Santana, 2009, p.11-56.
} 
ferramenta, o texto de Daniel, capitulo 7, será usado para compreender a leitura que o autor, ou autores, faz de seu tempo, que é a história do Médio Crescente Helenístico. ${ }^{4}$

\section{RESULTADOS E/OU DISCUSSÃO}

Selêucidas e Ptolomeus se confrontam pelo corredor da Palestina, faixa de importante acesso comercial, ambos desejando a expansão territorial. Os judeus, que são expectadores e sofredores dessa guerra, ficaram sujeitos à um novo governante, Antíoco III, rei dos selêucidas. Este garante a liberdade política e religiosa dos judeus, além de incentivos e benefícios, em troca de cooperação e submissão. ${ }^{5}$

Antíoco IV, novo governante depois de Antíoco III, levou o reino para guerrear contra os Ptolomeus, e sua campanha contra o Egito não foi efetivada por conta da intervenção romana. Desejando resolver os conflitos sociais e econômicos, referentes à sua derrota, intrometeu nos santuários locais e suas finanças. Queria reforçar as cidades gregas e impor a paideusis aos súditos. Essa interferência foi algo incomum, e mais do que conflitos internos do reino, o que resultaria em uma guerra santa dos judeus liderada por Judas Macabeu. ${ }^{6}$

O conflito interno maior, começa com Antíoco IV Epifânio proibindo praticas litúrgicas e tradicionais dos judeus, como a guarda do sábado e as festas religiosas, forçando o Helenismo e matando quem se opusesse, colocando judeus helenizados no poder em troca de dinheiro, e transformando o templo de YHWH no templo de Zeus. ${ }^{7}$

A literatura apocalíptica mede força com o poder do império e a situação opressiva. Os seres apresentados como bestiais, os animais, são lidos como representações dos impérios pelos quais o povo judeu foi dominado sucessivamente após a saída do Egito, aproximadamente no século X a.E.C. até o século II a.E.C., onde esses governos monstruosos são os responsáveis por provocar o caos cúltico, político e, consequentemente, social na judéia helenizada. ${ }^{8}$ O quarto animal é indescritível, monstruoso, que tudo destrói, consome e pisa, ele possui um chifre pequeno e Chevitarese entende, com a descrição do chifre pequeno que proferia palavras arrogantes, no versículo 8 do capítulo 7 do livro, Antíoco IV Epífânio que demonstrava eloqüência e ao mesmo tempo seu caráter blasfemo. ${ }^{9}$

O último ser é de outra natureza, pois é representado como tendo uma aparência humana e tem função distinta às descrita sobre os parecidos com animais, que o

\footnotetext{
${ }^{4}$ CHARTIER, Roger. O Mundo como Representação. Estudos avançados. São Paulo, v.5, n. 1, jan./abr. 1991, pp. 173-191.

${ }^{5}$ MOMIGLIANO, Arnaldo. Os Limites da Helenização: A interação cultural das civilizações grega, romana, céltica, judaica e persa. Tradução: Claudia Martinelli Gama. Jorge Zahar Editor. Rio de Janeiro, 1991. pp. 89-90.

${ }^{6}$ MOMIGLIANO, Arnaldo. Os Limites da Helenização: A interação cultural das civilizações grega, romana, céltica, judaica e persa. Tradução: Claudia Martinelli Gama. Jorge Zahar Editor. Rio de Janeiro, 1991. pp. 91.

7 ADEMAR KAEFER, José. "Bem-aventurado aquele que perseverar" (Dn 12,12) Uma introdução ao livro de Daniel. pp. 6.

${ }^{8}$ COLLINS, John J. A imaginação apocalíptica: Uma introdução à literatura apocalíptica judaica. São Paulo: Paulus, 2010. pp. 154.

${ }^{9}$ CHEVITARESE, André L. CORNELLI, Gabriele. Judaísmo, cristianismo e helenismo: ensaios acerca das interações culturais no Mediterrâneo Antigo. São Paulo: Annablume; Fapesp, 2007. pp. 34.
} 
antecedem. Essa imagem humana, que vem dos céus e recebe o poder para governar, representa a resistência contra o poder desumano e desumanizador do Estado. ${ }^{10}$

\section{CONSIDERAÇÕES FINAIS}

O apocalipse de Daniel tem como objetivo responder às circunstancias de seu tempo, sob o domínio de um império explorador e opressor. Por estas características negativas o império dominante é comparado ao monstro, ao bestial. Ele é o desumano que desumaniza, de aparência terrível e que a tudo destrói. Em contramão desse poder caótico está a figura do humano, que independente de ser a representação de um povo, grupo ou indivíduo, representa antes de tudo a esperança de um reino humanizante. A resistência à cultura Helênica em troca de um conservadorismo cultural, que tem por base no discurso eu-tu com Deus, é um conflito entre dois modos de vida. Os fiéis, santos do altíssimo, não abriram mão da sua tradição e nem de seu Deus, valorizando sua heterogeneidade diante do helenismo, que por sua vez tinha características homogeneizantes. O texto é uma bandeira para o discurso da liberdade contra os poderes dominantes, como por exemplo o Estado. Também o discurso da esperança, não passiva, mas sim ativa e reativa, que caminha em direção ao fim. Fim esse que valoriza a justiça, respondendo com o descanso aos que sofrem.

\section{REFERÊNCIAS}

ADEMAR KAEFER, José. "Bem-aventurado aquele que perseverar" (Dn 12,12) Uma introdução ao livro de Daniel.

BLOCH, Marc. Apologia da História. Jorge Zahar: Rio de Janeiro, 2001.

CHARTIER, Roger. O Mundo como Representação. Estudos avançados. São Paulo, v.5, n. 1, jan./abr. 1991.

CHEVITARESE, André L. CORNELLI, Gabriele. Judaísmo, cristianismo e helenismo: ensaios acerca das interações culturais no Mediterrâneo Antigo. São Paulo: Annablume; Fapesp, 2007.

COLLINS, John J. A imaginação apocalíptica: Uma introdução à literatura apocalíptica judaica. São Paulo: Paulus, 2010.

MOMIGLIANO, Arnaldo. Os Limites da Helenização: A interação cultural das civilizações grega, romana, céltica, judaica e persa. Tradução: Claudia Martinelli Gama. Jorge Zahar Editor. Rio de Janeiro, 1991.

SOUSA, Ágabo Borges de. A Figura de "Um como um Filho de um Homem" em Daniel 7 - O Messias na compreensão de Daniel.

${ }^{10}$ SOUSA, Ágabo Borges de. A Figura de "Um como um Filho de um Homem” em Daniel 7 - O Messias na compreensão de Daniel. pp. 77. 
, Livros dos Inícios e Princípios: O Livro de Gênesis como Base Teológica para a Bíblia Hebraica. Epistêmê V1.11, Feira de Santana, 2009. 